\title{
Hybrid repair of complex thoracoabdominal aortic aneurysms using applied endovascular strategies combined with visceral and renal revascularization
}

\author{
Lukla Biasi, MD, Tahir Ali, MBChB, MRCS, Tom Loosemore, MBBS, FRCS, MS, \\ Rob Morgan, MBBS, MRCP, FRCR, Ian Loftus, MBBS, FRCS, MD, and \\ Matt Thompson, MA, MBBS, FRCS, MD
}

Objective: We sought to report our experience with combined retrograde visceral revascularization and endovascular exclusion (hybrid procedure) of thoracoabdominal aortic aneurysms.

\begin{abstract}
Methods: From February 2005 to October 2007, the prospectively collected data of 18 consecutive patients undergoing hybrid repair were analyzed. Median age was 73 years; Crawford-Safi extent included 2 type I, 8 type II, 7 type III, and 1 type V thoracoabdominal aortic aneurysms; 13 were atherosclerotic and 5 were postdissecting aneurysms. Previous open or endovascular aortic surgery had been performed in $11(61.1 \%)$ patients. Society for Vascular Surgery/North American Chapter of the International Society for Cardiovascular Surgery preoperative risk stratification identified mild-to-severe hypertension and pulmonary and cardiac status in $88.9 \%, 67.7 \%$, and $88.9 \%$ of the patients, respectively.
\end{abstract}

\begin{abstract}
Results: Fifty-four visceral vessels were bypassed in 18 patients. As an adequate inflow site, the common iliac artery was identified in $15(83.3 \%)$ patients, the infrarenal native aorta was identified in $1(5.6 \%)$ patient, and a previous tube graft was identified in $2(11.1 \%)$ patients. Median operating time was 360 minutes (range, 210-600 minutes), and median blood loss was $3200 \mathrm{~mL}$ (range, 1000-18,000 mL). Aneurysm exclusion was achieved in 17 patients. Thirty-day mortality was $16.7 \%(\mathrm{n}=3 / 18)$. Complications included paraplegia $(\mathrm{n}=1)$ and acute myocardial infarction $(\mathrm{n}=2)$. Median follow-up was 23 months (range, $8-42$ months), with visceral graft patency at follow-up or death of $98.1 \%(n=53 / 54)$. One early and 1 late type Ia endoleak $(11.8 \%, n=2 / 17)$, no type III endoleaks, and 5 type II endoleaks were detected, none necessitating adjuvant procedures.
\end{abstract}

Conclusion: The visceral hybrid repair is a feasible and relatively safe procedure for extensive thoracoabdominal aortic aneurysms. Even considering the significantly high mortality and morbidity rates, it might represent a viable alternative in a cohort of patients historically deemed at high risk for traditional surgical intervention. ( $\mathrm{J}$ Thorac Cardiovasc Surg 2009;138:1331-8)

Aneurysm resection and prosthetic graft replacement have formed the mainstay of surgical treatment for thoracoabdominal aortic aneurysms (TAAAs). With this technique, patient mortality is related to the period of aortic occlusion, operative blood loss, extent of the aneurysm, and patient comorbidity. ${ }^{1}$ Most units use adjunctive strategies, such as left heart bypass, selective perfusion, and the routine drainage of cerebrospinal fluid (CSF), to improve outcomes. ${ }^{2,3}$ In spite of these adjunctive techniques, many patients with signifi-

\footnotetext{
From St George's Regional Vascular Institute, St Georges Hospital NHS Trust, London, United Kingdom.

Disclosures: Matt Thompson reports consulting fees from medtronic and Cook; Ian Loftus reports consulting fees from Medtronic.

Received for publication May 13, 2008; revisions received Dec 3, 2008; accepted for publication March 21, 2009; available ahead of print May 28, 2009.

Address for reprints: Matt Thompson, MA, MBBS, FRCS, MD, St George's Regional Vascular Institute, 4th Floor, St James Wing, St Georges Hospital NHS Trust, Blackshaw Rd, London SW17 0QT, United Kingdom (E-mail: matt.thompson@ stgeorges.nhs.uk).

$0022-5223 / \$ 36.00$

Copyright (C) 2009 by The American Association for Thoracic Surgery

doi:10.1016/j.jtcvs.2009.03.032
}

cant comorbidity are unable to undergo operative repair because of a high predicted perioperative mortality.

The mortality and morbidity rates after conventional repair of TAAAs are still significant, with specialized centers reporting mortality rates of $5 \%$ to $16 \%$ and paraplegia rates of $4 \%$ to $11 \%{ }^{4-7}$ However, these excellent results are not representative of outcomes outside of these centers, with national/community mortality rates exceeding $20 \%$ at 30 days and $30 \%$ at 1 year. $^{8}$

The application of combining surgical and endovascular strategies in the management of complex aortic disease has been suggested to reduce the surgical insult by obviating the need for thoracotomy and aortic crossclamping while also reducing the duration of visceral and renal ischemia. The exclusion of TAAAs by means of an endoluminal stent graft delivered through a remote arteriotomy or conduit requires sufficient length of proximal and distal landing zones (DLZs) in nondiseased or replaced aortas and is also required to safeguard perfusion of the gut and kidneys.

A hybrid repair can be defined as a combined surgical and endovascular approach in which transperitoneal retrograde 


\section{Abbreviations and Acronyms}

ASA = American Society of Anesthesiologists

$\mathrm{CSF}=$ cerebrospinal fluid

DLZ = distal landing zone

PLZ = proximal landing zone

SMA $=$ superior mesenteric artery

TAAA $=$ thoracoabdominal aortic aneurysm

visceral revascularization is used to create an adequate DLZ for endovascular TAAA endograft exclusion. The retrograde visceral bypass maintains perfusion to the visceral and renal arteries. This approach can be combined with great vessel transposition or bypass to create an adequate proximal attachment site for the thoracoabdominal endograft.

Initial enthusiastic reports from small case series have reported that the hybrid repair of TAAAs is feasible, even in high-risk patients, and that successful aneurysm exclusion can be achieved in the majority of patients, with satisfactory patient outcomes. ${ }^{9}$ The incidence of visceral bypass graft occlusions and sustained type I endoleaks and the durability of endograft design have not yet been completely defined in the literature. ${ }^{10}$ We report our preliminary experience with a cohort of 18 consecutive patients.

\section{MATERIALS AND METHODS \\ Patients}

From February 2005 to October 2007, the prospectively collected hospital records of 18 consecutive patients who had undergone combined visceral revascularization and endovascular stenting of complex TAAAs were analyzed (Figures 1 and 2).

Primary preoperative diagnostic imaging was obtained in all patients by means of 64-slice computed tomographic scanning of the thorax, abdomen, and pelvis. All patients were assessed for evidence of concomitant carotid artery disease with preoperative duplex scanning, and cardiac evaluation used dobutamine stress echocardiography. In 5 patients radionucleotide excretion renography (mercapto-acetyltriglycine) was necessary to evaluate dynamic renal function and dominance before proceeding to renal revascularization.

TAAAs were classified according to the revised Crawford-Safi TAAA extent classification into types II $(\mathrm{n}=8)$, III $(\mathrm{n}=7), \mathrm{I}(\mathrm{n}=2)$, and V $(\mathrm{n}=1)$. The study group comprised $10(55.6 \%)$ men and $8(44.4 \%)$ women with a median age of 73 years (range, 50-79 years).

Eleven $(61.1 \%)$ patients had undergone previous aortic operations (13 procedures). Seven of these patients had a history of either open or endovascular abdominal aortic aneurysm repair (2 patients for ruptured infrarenal aneurysm), and 6 patients had undergone earlier TAAA repair ( 1 patient with aortic root replacement, a further patient having had a total intrathoracic aortic arch debranching in addition to aortic root and valve replacement, and 3 patients undergoing thoracic endovascular aneurysm repair).

The median maximum aneurysm diameter was $65 \mathrm{~mm}$ (range, 45-96 $\mathrm{mm})$, with the majority of aneurysms being atherosclerotic in cause $(\mathrm{n}=$ $13,72.2 \%$ ). The remaining 5 patients had previous chronic aortic dissections with aneurysmal degeneration, of which 2 occurred in patients with underlying Marfan syndrome.

The median maximum diameter of chronic dissecting aneurysms was 64 $\mathrm{mm}$ (range, $58-85 \mathrm{~mm}$ ). The distance between the intimal tear and the left subclavian artery was less than $10 \mathrm{~mm}$ in 2 patients requiring supra-aortic vessel bypass. The chronic dissection involved the celiac trunk and superior

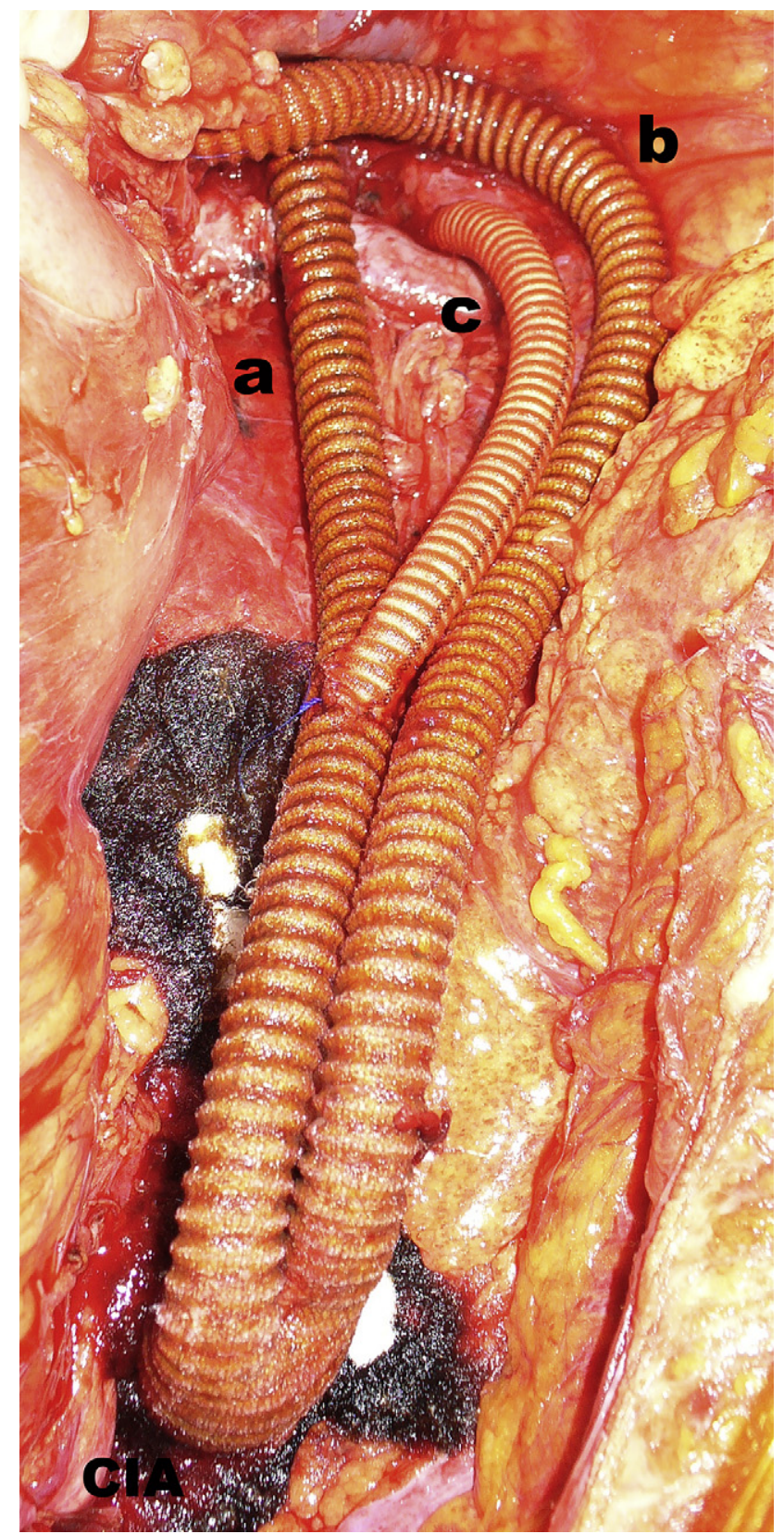

FIGURE 1. Intraoperative 3-vessel debranching. An inverted, bifurcated, 16- $\times 8-\mathrm{mm}$, silver-bonded Dacron graft fashioned end-to-side to the left common iliac artery (CIA) bypassing to the celiac trunk $(a)$ and superior mesenteric artery $(b)$ is shown. The left renal artery $(c)$ is revascularized with a separate 6-mm Dacron graft by using an end-to-end distal anastomosis and an end-to-side proximal anastomosis to one limb of the inflow graft.

mesenteric artery (SMA) in 3 patients and all 4 visceral vessels in a further 2 patients. In relation to our previous experience, the indication for treatment was sac enlargement in chronic postdissecting aneurysms involving the visceral patch, evidence of distal fenestrations, or both. ${ }^{11}$

Individual patient risk factors and comorbidities were recorded according to the Society for Vascular Surgery/North American Chapter of the International Society for Cardiovascular Surgery (Table 1). All patients undergoing elective and urgent operations had been preoperatively classified as American Society of Anesthesiologists (ASA) class 3 or 4 on the basis 


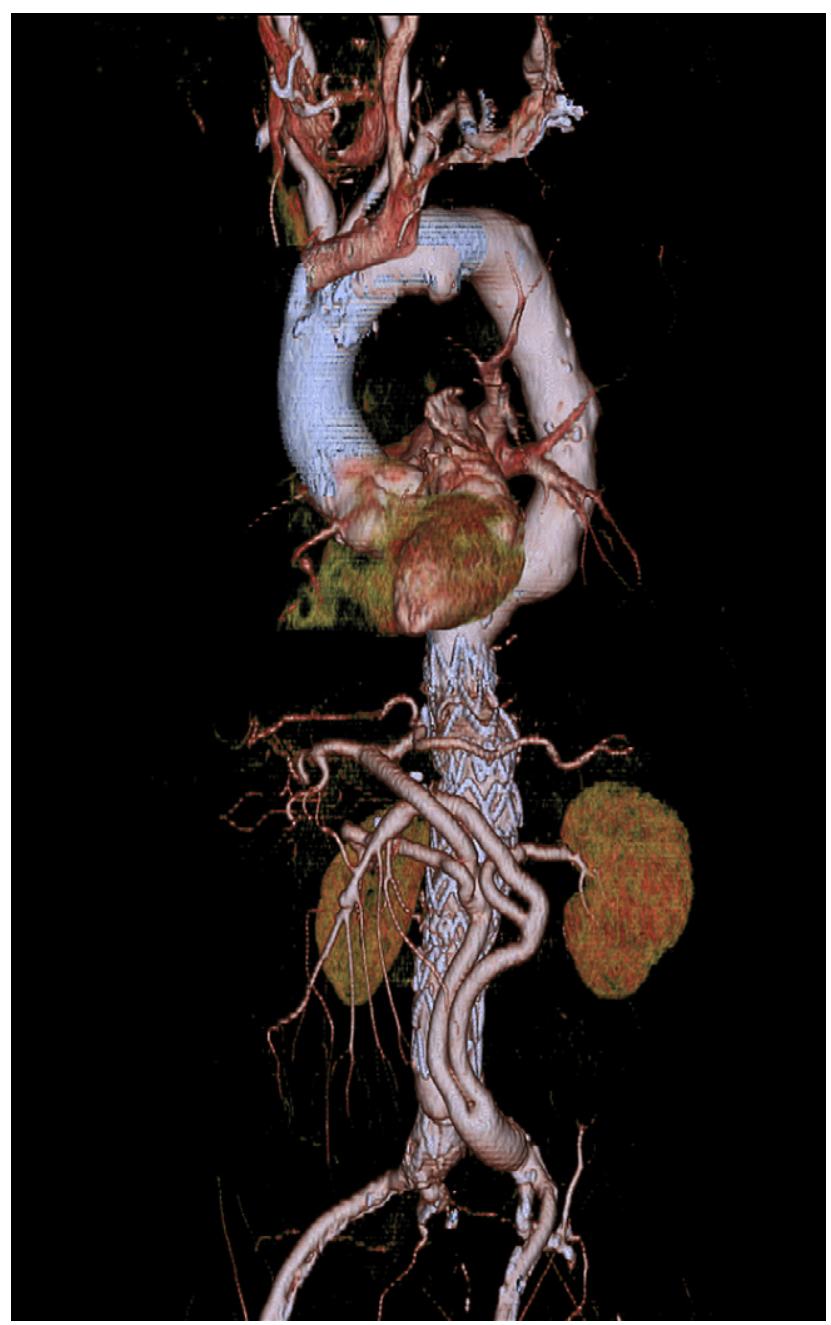

FIGURE 2. Postoperative computed tomographic angiograph (3-dimensional rendering) of a completed hybrid. Four-vessel visceral debranching (inverted, bifurcated, 16- $\times 8-\mathrm{mm}$ Dacron graft from the left common iliac artery to the celiac trunk and superior mesenteric artery and separate 6-mm Dacron grafts from each limb of the inflow graft to the left and right renal arteries) with thoracoabdominal aortic aneurysm endovascular exclusion (Medtronic Valiant endografts) is shown.

of the ASA Physical Status Classification System; patients undergoing emergency operations were classified as ASA class 5.

Elective repairs were undertaken in $14(77.8 \%)$ patients. Two $(11.1 \%)$ patients required urgent procedures for symptomatic TAAAs, and a further $2(11.1 \%)$ patients were treated on an emergency basis for radiologically proved aneurysm rupture in the presence of hemodynamic instability (1 thoracic and 1 abdominal rupture).

\section{Hybrid Procedure: Surgical Technique and Considerations}

Five $(27.8 \%)$ patients in this series were treated within a single hospital admission with simultaneous surgical and endovascular procedures, with endograft deployment proceeding immediately after visceral vessel debranching in the operating suite. The remaining patients $(n=13)$ underwent staged exclusion of the aortic aneurysm.

The median duration between initial visceral revascularization and final endovascular exclusion of the TAAA was 112 days (range, 49-240 days).
TABLE 1. Patient risk factor grading system for cardiovascular risk factors and comorbidity tabulated according to the Society for Vascular Surgery/North American Chapter of the International Society for Cardiovascular Surgery $(n=18)$

\begin{tabular}{lrccc}
\hline \multicolumn{1}{c}{ Risk factor } & None (\%) & Mild (\%) & Moderate (\%) & Severe (\%) \\
\hline Diabetes mellitus & $15(83.3)$ & $2(11.1)$ & $1(5.6)$ & 0 \\
Tobacco use & $3(16.7)$ & $5(27.8)$ & $6(33.3)$ & $4(22.2)$ \\
Hypertension & $3(16.7)$ & $8(44.4)$ & $4(22.2)$ & $3(16.7)$ \\
Hyperlipidemia & $4(22.2)$ & $5(27.8)$ & $3(16.7)$ & $6(33.3)$ \\
Cardiac status & $11(61.1)$ & $4(22.2)$ & $2(11.1)$ & $1(5.6)$ \\
Carotid status & $12(66.7)$ & $3(16.7)$ & $3(16.7)$ & 0 \\
Renal status & $15(83.3)$ & $3(16.7)$ & 0 & 0 \\
Pulmonary status & $6(33.3)$ & $6(33.3)$ & $5(27.8)$ & $1(5.6)$ \\
\hline
\end{tabular}

The median delay between stage I and II was prolonged by 5 outliers (>120 days): 3 patients who required custom-made endografts, 1 who required coronary revascularization, and 1 with chronic obstructive pulmonary disease who underwent pulmonary rehabilitation in between stages.

No patient died from aneurysm-related rupture in this period, but $1 \mathrm{pa}-$ tient died in the early postoperative period, precluding subsequent endovascular repair, as a result of embolic left colonic infarction and subsequent multiorgan failure on the third postoperative day.

\section{Visceral Debranching}

Surgical intervention was performed after achievement of general and epidural anesthesia with the patient lying supine. A midline transperitoneal incision was preferentially used to gain access to the visceral, renal, and inflow vessels. Inflow for retrograde revascularization was evaluated in each patient on the basis of preoperative imaging and confirmed with intraoperative findings. Preferentially, inflow was obtained from the right common iliac artery in most patients by means of an inverted, $16 \times 8-\mathrm{mm}$, silver-impregnated, rifampicin-bonded Dacron graft fashioned end-to-side to the common iliac artery $(n=15)$. Where the aorta had been previously repaired with a graft (previous abdominal aortic aneurysm open repair in 2 patients), an end-to-side anastomosis was fashioned to the distal aspect of the graft, allowing for a sufficient DLZ at subsequent endograft deployment. The native infrarenal aorta was used in 1 patient who had a type V TAAA with an uninvolved infrarenal abdominal aorta. In 1 female patient with small native common iliac arteries and a type I TAAA, right and left common iliac arteries were used individually for inflow sources for the celiac trunk and SMA, respectively.

End-to-side anastomosis from the limb of the inflow graft to the SMA was fashioned with a lazy $\mathrm{C}$ configuration. The other limb of the bifurcated inflow graft was anastomosed to a branch of the celiac axis by using a tunneled retropancreatic approach. Each individual renal artery, where indicated, was revascularized with a separate 6-mm Dacron graft by using an end-to-end anastomosis with an end-to-side proximal anastomosis to each limb of the inflow graft. The celiac trunk and SMA were subsequently double ligated at their origin with nonabsorbable sutures and metal clips, and the peritoneum or omentum was used to cover any exposed graft material.

In 4 cases a further 10-mm Dacron prosthetic conduit was fashioned endto-side to either the aortic graft $(n=1)$ or iliac graft $(n=3)$ to anastomose distally to the common femoral artery $(\mathrm{n}=2)$ or the superficial femoral artery $(\mathrm{n}=2)$ to overcome severe anatomic limitations of native access vessels, which might have hindered subsequent endovascular stent delivery.

\section{RESULTS}

A total of 54 visceral vessels were bypassed in 18 patients (Table 2). Eight (44.4\%) patients underwent a complete retrograde, 4-vessel, debranching revascularization, and in the 
TABLE 2. Details of retrograde visceral revascularization and endovascular exclusion in a cohort of 18 patients with TAAAs

\begin{tabular}{|c|c|c|c|c|c|c|}
\hline Patient no. & Inflow & $\begin{array}{l}\text { Details of visceral } \\
\text { debranching }\end{array}$ & $\operatorname{PLZ}(\mathbf{m m})$ & $\operatorname{DLZ}(\mathbf{m m})$ & $\begin{array}{l}\text { Manufacturer of } \\
\text { endograft }\end{array}$ & $\begin{array}{c}\text { Adjunctive surgical } \\
\text { or endovascular procedures }\end{array}$ \\
\hline 1 & Right CIA & $\begin{array}{l}\text { SMA + common } \\
\text { hepatic artery }+ \text { right renal }\end{array}$ & $3(30)$ & $0(26)$ & Zenith Cook (branched) & Proximal cuff \\
\hline 2 & Right CIA & $\begin{array}{l}\text { SMA }+ \text { common } \\
\text { hepatic artery }\end{array}$ & $3(30)$ & $2(26)$ & Valiant & \\
\hline $3 *$ & Left CIA & SMA + splenic artery & $4(38)$ & $2(32)$ & Zenith & Proximal cuff \\
\hline 4 & Left CIA & $\begin{array}{l}\text { SMA + common } \\
\text { hepatic artery + right } \\
\text { renal + left } \\
\text { renal + graft-SFA }\end{array}$ & & & & \\
\hline $5^{*}$ & Infrarenal aorta & $\begin{array}{l}\text { SMA + common } \\
\text { hepatic artery }+ \text { graft-SFA }\end{array}$ & $4(40)$ & $2(34)$ & Valiant Talent & \\
\hline 6 & Right CIA & $\begin{array}{l}\text { SMA }+ \text { common } \\
\text { hepatic artery }+ \text { right renal }\end{array}$ & $3(38)$ & $0(27)$ & $\begin{array}{l}\text { Valiant Zenith } \\
\text { Cook (fenestrated) }\end{array}$ & \\
\hline 7 & Right and left CIA & $\begin{array}{r}\text { SMA + common } \\
\text { hepatic artery }\end{array}$ & $3(28)$ & $2(26)$ & Valiant & \\
\hline $8^{*}$ & Right CIA & $\begin{array}{r}\text { SMA + common } \\
\text { hepatic artery }\end{array}$ & $1(34)$ & $2(30)$ & Valiant & $\begin{array}{l}\text { Carotid-carotid to subclavian } \\
\text { bypass renal stent, } \\
\text { iliac stent }\end{array}$ \\
\hline $9 *$ & Right CIA & $\begin{array}{l}\text { SMA + common } \\
\text { hepatic artery + right } \\
\text { renal + left renal }\end{array}$ & $3(30)$ & $0(28)$ & Valiant Talent & \\
\hline $10 *$ & Right CIA & $\begin{array}{l}\text { SMA + left } \\
\quad \text { gastric artery }+ \text { right } \\
\text { renal }+ \text { left renal }\end{array}$ & $2(34)$ & $0(28)$ & Valiant & Carotid subclavian bypass \\
\hline 11 & Infrarenal aortic graft & SMA + graft-right CFA & $3(32)$ & $2(26)$ & Valiant & \\
\hline 12 & Right CIA & $\begin{array}{r}\text { SMA + common } \\
\text { hepatic artery }\end{array}$ & $3(38)$ & $0(28)$ & $\begin{array}{l}\text { Valiant Zenith } \\
\text { Cook (fenestrated) }\end{array}$ & 2 cuffs, Palmaz stent \\
\hline 13 & Infrarenal aortic graft & $\begin{array}{l}\text { SMA + common } \\
\text { hepatic artery + right } \\
\text { renal + left } \\
\text { renal + graft-CFA }\end{array}$ & $3(32)$ & $0(24)$ & Valiant & \\
\hline 14 & Right CIA & $\begin{array}{l}\text { SMA + right } \\
\text { renal + left renal }\end{array}$ & $3(38)$ & $0(24)$ & Valiant & \\
\hline 15 & Right CIA & $\begin{array}{l}\text { SMA + common } \\
\text { hepatic artery + right } \\
\text { renal }+ \text { left renal }\end{array}$ & $3(38)$ & $0(24)$ & Valiant & \\
\hline 16 & Left CIA & $\begin{array}{l}\text { SMA + common } \\
\text { hepatic artery + right } \\
\text { renal }+ \text { left renal }\end{array}$ & $2(36)$ & $0(23)$ & Valiant Talent & Carotid subclavian bypass \\
\hline 17 & Left CIA & $\begin{array}{l}\text { SMA + common } \\
\text { hepatic artery + right } \\
\text { renal }+ \text { left renal }\end{array}$ & $3(32)$ & $0(20)$ & Valiant & \\
\hline 18 & Right CIA & $\begin{array}{l}\text { SMA + common } \\
\text { hepatic artery }+ \text { right } \\
\text { renal }+ \text { left renal }\end{array}$ & $2(34)$ & $0(24)$ & Valiant & Carotid subclavian bypass \\
\hline
\end{tabular}

Patient number 4 died before stage II. PLZ, Proximal landing zone; $D L Z$, distal landing zone; $C I A$, common iliac artery; SMA, superior mesenteric artery; $S F A$, superficial femoral artery; $C F A$, common femoral artery. *Postdissecting aneurysm.

majority of cases ( $\mathrm{n}=16,88.9 \%)$, both the celiac trunk and SMA were revascularized. The only 2 exceptions were an asymptomatic chronic occlusion of the celiac trunk identified preoperatively and a celiac trunk that could not be adequately exposed because of densely adherent scar tissue in a patient who had previous hepatic surgery. The celiac trunk was revascularized to the common hepatic artery in the majority of instances $(n=14)$ and on 1 occasion each to the splenic artery $(n=1)$ and the left gastric artery $(n=1)$. Four renal arteries in 3 patients were not bypassed because of scarring or the hemodynamic instability of the patient, requiring ensuing revascularization with custom-made 
fenestrated or branched stent grafts at the subsequent admission for endovascular exclusion of the aneurysm.

Hybrid procedures in 3 patients with hourglass-shaped aneurysms allowed for preservation of renal ostia without the need for revascularization.

The median operative time for retrograde revascularization was 360 minutes (range, 210-600 minutes), with a median estimated blood loss of $3200 \mathrm{~mL}$ (range, 1000-18,000 mL).

Three patients in this series required intraoperative splenectomy for inadvertent injury to this organ during surgical intervention. No other major intraoperative complications were recorded. Median stay within the intensive care unit was 3 days (range, 1-14 days).

\section{Endovascular Procedure}

Common femoral artery access for the endovascular repair was achieved controlateral to the site of retrograde inflow. This negated the risk of iatrogenic trauma or intimal dissection to the vessels during endograft insertion. Routine perioperative CSF drainage was not performed in this series of patients. Patients were woken immediately after the endovascular repair to assess neurologic function, and any patient with potential spinal cord ischemia had a spinal drain placed. In the latter part of the series, any patient undergoing left subclavian artery coverage had a carotid-subclavian artery bypass.

The extent of thoracoabdominal endografting was defined according to Ishimaru's mapping of thoracic aorta (proximal landing zone [PLZ], 0-4) and Chiesa's mapping of the abdominal aorta (DLZ, 4-0; Table 2). ${ }^{12,13}$ The most commonly used endograft stents were the Valiant, Talent (Medtronic, Santa Rosa, Calif), and Zenith (Cook, Bloomington, Ind). In addition, 2 custom-made renal-fenestrated and 1 branched Cook endograft (Cook, Brisbane, Australia) were used in the attempt to revascularize 4 renal arteries in 3 patients.

The median proximal neck diameter was $34 \mathrm{~mm}$ (range, 28-40 mm), and the median distal neck diameter was $28 \mathrm{~mm}$ (range, 26-34 $\mathrm{mm}$ ) at DLZ 2 and $24 \mathrm{~mm}$ (range, 20-28 mm) at DLZ 0.

The distal neck was deemed hostile in 4 patients, with endoluminal thrombus of greater than $50 \%$ in $11.1 \%(\mathrm{n}=$ $2 / 18$ ) and wall calcifications of greater than $40 \%$ in $16.7 \%$ $(\mathrm{n}=3 / 18)$. The remaining 6 patients presented with a more favorable neck morphology. The presence of adverse aortic morphology in the distal neck was not associated with a need for early reintervention for type $1 \mathrm{~b}$ endoleaks in this series. ${ }^{14}$

Endograft diameters and lengths were selected to allow a $10 \%$ to $20 \%$ oversizing requirement (depending on the cause and anatomic characteristics) and stent overlap of at least $3 \mathrm{~cm}$. PLZs in Safi-Crawford type III, IV, and V aneurysms used all available descending thoracic aortas up to the left subclavian artery origin. In type I and II TAAAs, the
PLZ was mandated by aneurysm morphology and the need for supra-aortic trunk transposition.

Technical success, as defined by aneurysm exclusion without intraprocedural evidence of type 1 or type 3 endoleaks, was achieved in 16 patients. In 1 patient on-table angiographic analysis showed the presence of a type 1a endoleak from the PLZ, ${ }^{2}$ which, despite a Valiant proximal extension cuff, could not be fully corrected. Myocardial ischemia in this patient prevented placement of further proximal endografts.

\section{Mortality}

The overall 30-day mortality in this patient cohort was $16.7 \%(n=3 / 18)$, irrespective of elective, urgent, or emergency presentation. One of these deaths occurred after visceral debranching (attributed to embolic intestinal infarction and subsequent multiple organ failure), and therefore the endovascular repair was not performed.

Of those patients who had undergone complete aneurysm exclusion, 1 died as a result of aspiration pneumonia on day 6 after simultaneous repair of a postdissection type II TAAA, and a further patient died after a middle cerebral artery stroke following a staged visceral and supra-aortic trunk debranching and subsequent endovascular exclusion of a postdissection type II TAAA. Cumulative mortality at last follow-up was $22.2 \%(n=4 / 18)$ : only 1 patient died postoperatively (on day 65) after a severe acute myocardial infarction.

\section{Morbidity}

One patient in this series had delayed lower limb paraplegia after repair of a type II TAAA. Signs of motor and sensory loss at the level of T-10 occurred 4 days after completion of a staged hybrid repair, and this did not improve in spite of CSF drainage. At the latest clinical follow-up (34 months), the patient demonstrated partial neurologic improvement.

Other complications after visceral revascularization included acute myocardial infarction in 2 patients with pre-existing coronary heart disease. In 1 patient this was identified intraoperatively, and the patient subsequently underwent coronary artery bypass grafting before a staged endovascular repair. The other patient presented on an emergency basis with a ruptured TAAA and did not require further coronary revascularization.

Two kidneys in 2 patients, who were deemed suitable for custom-made fenestrated or branched endografts, were sacrificed as a result of an inability to place a covered stent in the target renal vessel. This did not have any determinable effect on renal function in these patients.

No patients required positive-pressure ventilatory assistance or intubation for longer than 7 days, but postoperative infective respiratory complications occurred in 2 patients. 
The incidence of multisystem organ dysfunction was $22.2 \%$ $(n=4 / 18) .{ }^{15}$ Three of these patients died. Overall, 55.6\% $(n=10 / 18)$ of the patients did not have any perioperative complications at last follow-up.

\section{Hospital Stay}

Median length of stay after visceral and renal revascularization was 18 days (range, 5-42 days). Subsequent admissions for endovascular stenting required a further median length of stay of 7 days (range, 3-13). Patients treated within a single hospital admission were discharged at a median of 15 days (range, $9-19$ days).

\section{Follow-up}

All surviving patients were discharged from the hospital with a clinic review at 6 weeks. Subsequent follow-up and surveillance imaging as per protocol with both computed tomographic and Duplex scan surveillance were scheduled at 1,6 , and 12 months and annually thereafter.

At death or a median follow-up of 23 months (range, 8-42 months), all but 1 (53/54) of the visceral grafts remained patent ( $98.1 \%$ patency rate). Postmortem examination in all 3 deceased patients did not reveal graft thrombosis.

One celiac artery graft anastomosed to the common hepatic artery occluded in the time interval between visceral revascularization and endograft insertion but was not associated with symptoms of acute or chronic intestinal ischemia.

\section{Endoleaks}

The cumulative incidence of type I endoleak was $11.8 \%$ $(\mathrm{n}=2 / 17)$. One required an adjunctive carotid-carotid bypass and proximal endograft extension after detection of a late type 1a endoleak at 14 month's follow-up. The second patient had a type 1a endoleak detected intraoperatively that was not corrected despite the use of a Valiant Freeflo proximal component (Medtronic). Intraoperative myocardial ischemia prevented further intraoperative attempts at correction.

No type III endoleaks were seen. Five type II endoleaks, which did not necessitate further endovascular intervention, were identified. Of these, 2 resolved spontaneously at 13 and 7 months after exclusion, respectively, with the remaining patients not demonstrating any sac enlargement on subsequent radiologic surveillance.

\section{DISCUSSION}

Traditional surgical repair of extensive TAAAs carries an attendant risk of significant morbidity and mortality and precludes certain patients from undergoing open repair. Identifiable patient risk factors predicting adverse outcomes include emergency presentation, previous aortic replacement, diabetes, smoking history, renal and cardiorespiratory impairment, age greater than 79 years, acute dissection, and the extent of the TAAA.

Published series suggest a 30-day mortality rate approaching $50 \%$ in patients stratified as being at highest risk, thereby precluding their consideration for traditional surgical intervention. ${ }^{16}$

The hybrid technique of retrograde visceral revascularization followed by endoluminal exclusion of TAAAs has a theoretic advantage of averting the need for thoracotomy and supraceliac aortic crossclamping. This might result in improved intraoperative hemodynamic stability, a reduction in end-organ ischemia, and cardiopulmonary injury and could therefore present an acceptable alternative to open surgical intervention in high-risk patients.

Donas and colleagues ${ }^{9}$ identified 58 patients from 13 case series from 1999-2006 whose prior surgical histories and medical comorbidities had precluded open surgical repair and were treated with the hybrid approach. The authors of the study reported perioperative and midterm mortality rates of $10.7 \%$ and $15.5 \%$ (median follow-up of 14.2 months), respectively, with a reported graft patency of $97.8 \%$ (229/ 234 grafts). This study, however, was disadvantaged in that only 1 of the 13 case series included in the review/analysis had greater than 8 patients, and moreover, extensive TAAAs (Crawford type II) were underrepresented in these case series, comprising little over a third of the population studied. Our review of more recent and larger series (5 of which were not previously included) suggests that mortality rates can vary between $6.7 \%$ and $24 \%$ (Table 3). ${ }^{12,17-21}$ Variability in mortality reflects the learning curve, extent of the TAAA, and number of vessels targeted.

In all series of hybrid repair of TAAAs, anticipated rates of permanent spinal cord infarction have not materialized, despite extensive thoracoabdominal exclusion of aneurysmal aortas (type II and type III) in a majority of patients. Furthermore, despite the retrograde approach to visceral revascularization from iliac inflow vessels, the majority of conduits remained patent without end-organ ischemia.

In our practice we now advocate routine revascularization of the left subclavian artery before deploying endoluminal stents, which necessitate the coverage of the left subclavian origin. Recent reports from the European Collaborators on Stent/Graft Techniques for Aortic Aneurysm Repair registry support this policy, in which investigators have found that spinal cord ischemia is increased in patients in whom prophylactic revascularization of the subclavian artery is not undertaken before thoracic stent deployment. ${ }^{22-24}$ Our practice is not to perform routine CSF drainage in staged procedures but to assess the patient immediately after endograft placement. Confining CSF drainage to only those patients with neurologic deficit minimizes the inadvertent risk of spinal cord infection and bleeding associated with spinal catheter placement. ${ }^{25}$ The only spinal cord ischemia in our series presented late, and in our opinion the risk/benefit ratio does not 
TABLE 3. Tabulated summary of published series of combined surgical and endovascular repair of TAAAs (n > 10), January 2005-December 2007

\begin{tabular}{|c|c|c|c|c|c|c|c|c|c|}
\hline Authors & $\begin{array}{c}\text { Institution, year of } \\
\text { publication }\end{array}$ & No. & Type II & Type III & Vessels* & $\begin{array}{c}\text { Overall } \\
\text { mortality }\end{array}$ & $\begin{array}{l}\text { Spinal } \\
\text { deficit } †\end{array}$ & $\begin{array}{c}\text { Graft } \\
\text { patency }\end{array}$ & $\begin{array}{c}\text { Type } 1+3 \\
\text { leaks }\end{array}$ \\
\hline Resch and coworkers ${ }^{17}$ & Cleveland, 2005 & 13 & $38.5 \%$ & $15.4 \%$ & - & $23.1 \%$ & $30.7 \%(\mathrm{P}=2 / 4)$ & - & $23.1 \%$ \\
\hline Zhou and coworkers ${ }^{18}$ & Houston, 2006 & 15 & 0 & $53.3 \%$ & $40(2.7)$ & $6.7 \%$ & 0 & $95 \%$ & 0 \\
\hline Black and coworkers ${ }^{19}$ & $\begin{array}{l}\text { St Mary's } \\
\quad \text { London, } 2006\end{array}$ & 26 & $62 \%$ & $26.9 \%$ & $94(3.6)$ & $23 \%$ & 0 & $98 \%$ & $26.9 \%$ \\
\hline Bockler and cowoekres ${ }^{20}$ & Heidelberg, 2007 & 11 & $18.2 \%$ & $9.1 \%$ & - & - & 0 & - & $9.1 \%$ \\
\hline Chiesa and coworkers ${ }^{12}$ & Milan 2007 & 13 & $15.4 \%$ & 0 & $32(2.5)$ & $23.0 \%$ & $7.7 \%(P=0 / 1)$ & $100 \%$ & 0 \\
\hline Lee and coworkers ${ }^{21}$ & Gainesville, 2007 & 17 & $11.8 \%$ & $47.0 \%$ & $56(3.3)$ & $24.0 \%$ & 0 & $96 \%$ & $15.4 \%$ \\
\hline Our study & $\begin{array}{l}\text { St George's } \\
\text { London } 2008\end{array}$ & 18 & $44.4 \%$ & $38.9 \%$ & $54(3.0)$ & $16.7 \%$ & $5.6 \%(\mathrm{P}=1 / 1)$ & $98.1 \%$ & $11.8 \%$ \\
\hline
\end{tabular}

$P$, Permanent. Overall mortality indicates elective, urgent, and emergency procedures. *Average number of vessels revascularized per procedure from references. $\dagger$ Episodes of permanent neurologic deficit.

substantiate the use of prophylactic drainage, although we acknowledge that the series is relatively small.

Staged aneurysm exclusion of the TAAA is our preferred technique in the majority of patients undergoing elective procedures. No patients in this series died as a consequence of aneurysm rupture before final endoluminal exclusion, although this does remain a theoretic risk. The advantage of adopting a staged approach to these patients is that it allows for a shorter final endovascular procedure in hemodynamically stable patients who have not had to endure an extensive revascularization procedure and have not been subject to hypothermia, renal ischemia, and blood loss. This facilitates early extubation of the patient and immediate assessment of spinal cord status. Deferring final aneurysm exclusion until after visceral debranching also allows stent deployment to take place in an angiography suite with full access to dynamic computed tomography. The precise placement of the endoluminal stents in proximal thoracic aneurysms requires highquality dynamic angiography that is not always obtained by using an image intensifier in the operating theater.

In the present series the incidence of type I endoleaks was low. The largest previously reported series of 26 patients observed that 1 in 5 patients had type I endoleaks, half of which were not amenable to cure with further procedures. ${ }^{19}$ Despite the extensive stent coverage of the aorta, no type III endoleaks were seen in our patients.

Accurate comparative analysis of patients undergoing traditional TAAA repair versus hybrid operations cannot be made due to the disparity in both patient risk factors and the learning curve with the hybrid technique. The present study has demonstrated that successful outcome for patients after hybrid repair of TAAAs is feasible in a cohort of elderly patients historically deemed at high risk for traditional surgical repair. More than $80 \%$ of the patient cohort in the present series had type II or type III TAAAs, and more than $60 \%$ had a previous history of thoracotomy or aortic surgery. The median age of the patients was 73 years, the majority of whom had a history of chronic obstructive lung disease, hypertension, and impaired cardiac function (Table 4). ${ }^{4-7}$ The level of patient comorbidity appears to be greater than that seen in the cohorts of patients reported in the large single-center series of open TAAA repair. All patients had large aneurysms (median diameter, $65 \mathrm{~mm}$; range, 45-96 mm), which were at risk of rupture and deemed to require intervention. Overall patient perioperative mortality in our series was $16.7 \%$, which compares favorably to the outcomes reported in community series of all patients undergoing open repair and more favorable than for elderly patients deemed at high risk of open repair (30-day mortality of $50 \%$ ). ${ }^{16}$ Furthermore, risks of spinal paraplegia appear to be low despite the extensive nature of the aneurysms treated and are in keeping with the paraplegia rate reported by the European Collaborators on Stent/Graft Techniques for Aortic Aneurysm Repair investigators $(5.6 \% \text { vs } 4 \%)^{22}$ and significantly lower than that seen in patients undergoing traditional open type II repair (up to $25 \%){ }^{26}$ Cumulative incidence of perioperative complications was considerably high $(44.4 \%, \mathrm{n}=8 / 18)$, but this is lower than the cited outcomes reported after open repair of

TABLE 4. Comparative patient risk factors for undergoing hybrid repair versus traditional TAAA repair

\begin{tabular}{|c|c|c|c|c|c|c|}
\hline Authors & Age (y) & $\begin{array}{c}\text { Prior aortic } \\
\text { surgery (open/endo) }\end{array}$ & $\begin{array}{l}\text { Crawford } \\
\text { type II-III }\end{array}$ & COPD & Cardiac status & Hypertension \\
\hline Coselli and coworkers ${ }^{4}$ & 66.1 & $25.3 \%$ thoracic & $50.4 \%$ & $36.9 \%$ & $17.5 \%$ PTCA/CABG & $75.8 \%$ \\
\hline Safi and coworkers ${ }^{5}$ & 64.0 & $12.6 \%$ & $25.2 \%$ & $21.4 \%$ & $28.2 \%$ coronary artery disease & $73 \%$ \\
\hline Cambria and coworkers ${ }^{6}$ & 70.5 & $28.8 \%$ & $15.7 \%$ & $56.7 \%$ & - & $87.2 \%$ \\
\hline Estrera and coworkers ${ }^{7}$ & 67.0 & - & $34.5 \%$ & $33.5 \%$ & - & $76.8 \%$ \\
\hline Our study & 73.0 & $61.1 \%$ & $83.3 \%$ & $66.7 \%$ & $88.9 \%$ (SVS/ISCVS mild to severe) & $88.9 \%$ \\
\hline
\end{tabular}

COPD, Chronic obstructive pulmonary disease; $P T C A$, percutaneous transluminal coronary angioplasty; $C A B G$, coronary artery bypass grafting; SVS/ISCVS, Society for Vascular Surgery/North American Chapter of the International Society for Cardiovascular Surgery. 
TAAAs. ${ }^{27,28}$ Late mortality, at 23 month's median followup, was $22.2 \%(n=4 / 18)$. The small cohort of patients does not allow, at this point, a survival analysis, but the short-term results are encouraging.

Recent technologic advances in stent graft design have realized the possibility of deploying customized endografts with fenestrations, allowing target vessel cannulation with additional covered stents to afford antegrade perfusion of the visceral vessels. ${ }^{29}$ Similarly, branched endovascular grafts have also been successfully deployed, preserving end-organ perfusion in selected patients, and some TAAAs can now be treated with 4 -vessel branched grafts. ${ }^{30}$ The need for accurate measurements and precise manufacturing results in a lag time of several weeks in most, and anatomic constraints with access and vessel tortuosity might not allow all TAAAs to be treated with a total endovascular solution.

The emerging paradigm shift in the management of complex TAAAs has increased the number of therapeutic options available for repair. In low-risk patients it would appear that open repair in a high-volume center is the gold standard. In higher-risk patients visceral hybrid revascularization or total endovascular solutions might be preferred. In time, the number of visceral hybrid procedures is likely to decrease as branched grafts become more prevalent, although longer-term outcomes after hybrid repair are still awaited. However, the hybrid option is likely to remain a viable alternative to other modalities because not all TAAAs will be treatable by using total endovascular solutions because of anatomic constraints, and open repair might not be appropriate in high-risk patients.

\section{References}

1. Rectenwald JE, Huber TS, Martin TD, Ozaki CK, Devidas M, Welborn MB, et al. Functional outcome after thoracoabdominal aortic aneurysm repair. $J$ Vasc Surg. 2002;35:640-7.

2. Fehrenbacher JW, Hart DW, Huddleston E, Siderys H, Rice C. Optimal end-organ protection for thoracic and thoracoabdominal aortic aneurysm repair using deep hypothermic circulatory arrest. Ann Thorac Surg. 2007;83:1041-6.

3. Coselli JS, Lemaire SA. Tips for successful outcomes for descending thoracic and thoracoabdominal aortic aneurysm procedures. Semin Vasc Surg. 2008;21:13-20.

4. Coselli JS, Bozinovski J, Lemaire SA. Open surgical repair of 2286 thoracoabdominal aortic aneurysms. Ann Thorac Surg. 2007;83(suppl):S862-4.

5. Safi HJ, Estrera AL, Azizzadeh A, Coogan S, Miller CC III. Progress and future challenges in thoracoabdominal aortic aneurysm management. World J Surg. 2008;32:355-60.

6. Cambria RP, Clouse WD, Davison JK, Dunn PF, Corey M, Dorer D. Thoracoabdominal aneurysm repair: results with 337 operations performed over a 15-year interval. Ann Surg. 2002;236:471-9.

7. Estrera AL, Miller CC III, Chen EP, Meada R, Torres RH, Porat EE, et al. Descending thoracic aortic aneurysm repair: 12-year experience using distal aortic perfusion and cerebrospinal fluid drainage. Ann Thorac Surg. 2005;80:1290-6.

8. Rigberg DA, McGory ML, Zingmond DS, Maggard MA, Agustin M, Lawrence PF, et al. Thirty-day mortality statistics underestimate the risk of repair of thoracoabdominal aortic aneurysms: a statewide experience. I Vasc Surg. 2006;43:217-22.

9. Donas KP, Czerny M, Guber I, Teufelsbauer H, Nanobachvili J. Hybrid open-endovascular repair for thoracoabdominal aortic aneurysms: current status and level of evidence. Eur J Vasc Endovasc Surg. 2007;34:528-33.
10. Sayed S, Thompson MM. Endovascular repair of the descending thoracic aorta: evidence for the change in clinical practice. Vascular. 2005;13: 148-57.

11. Sayer D, Bratby M, Brooks M, Loftus I, Morgan R, Thompson M. Aortic morphology following endovascular repair of acute and chronic type B aortic dissection: implications for management. Eur J Vasc Endovasc Surg. 2008; 36:522-9.

12. Chiesa R, Tshomba Y, Melissano G, Marone EM, Bertoglio L, Setacci F, et al. Hybrid approach to thoracoabdominal aortic aneurysms in patients with prior aortic surgery. J Vasc Surg. 2007;45:1128-35.

13. Ishimaru S. [Endovascular stent-graft repair for thoracic aortic aneurysm]. Kyobu Geka. 2006;59(suppl):666-73.

14. Girdauskas E, Falk V, Kuntze T, Borger MA, Schmidt A, Scheinert D, et al. Secondary surgical procedures after endovascular stent grafting of the thoracic aorta: Successful approaches to a challenging clinical problem. J Thorac Cardiovasc Surg. 2008;136:1289-94.

15. Welborn MB, Oldenburg HS, Seeger JM. The relationship between visceral ischaemia, proinflammatory cytokines, and organ injury in patients undergoing thoracoabdominal aortic aneurysm repair. Crit Care Med. 2000;28: 3191-7.

16. Huynh TT, Miller CC III, Estrera AL, Porat EE, Safi HJ. Thoracoabdominal and descending thoracic aortic aneurysm surgery in patients aged 79 years or older. J Vasc Surg. 2002;36:469-75.

17. Resch TA, Greenberg RK, Lyden SP, Clair DG, Krajewski L, Kashyap VS, et al. Combined staged procedures for the treatment of thoracoabdominal aneurysms. J Endovasc Ther. 2006;13:481-9.

18. Zhou W, Reardon M, Peden EK, Lin PH, Lumsden AB. Hybrid approach to complex thoracic aortic aneurysms in high-risk patients: surgical challenges and clinical outcomes. J Vasc Surg. 2006;44:688-93.

19. Black SA, Wolfe JH, Clark M, Hamady M, Cheshire NJ, Jenkins MP. Complex thoracoabdominal aortic aneurysms: endovascular exclusion with visceral revascularization. J Vasc Surg. 2006;43:1081-9.

20. Bockler D, Schumacher H, Klemm K, Riemensperger M, Geisbusch P, Kotelis D, et al. Hybrid procedures as a combined endovascular and open approach for pararenal and thoracoabdominal aortic pathologies. Langenbecks Arch Surg. 2007; 392:715-23.

21. Lee WA, Brown MP, Martin TD, Seeger JM, Huber TS. Early results after staged hybrid repair of thoracoabdominal aortic aneurysms. J Am Coll Surg. 2007;205: 420-31.

22. Buth J, Harris PL, Hobo R, van ER, Cuypers P, Duijm L, et al. Neurologic complications associated with endovascular repair of thoracic aortic pathology: incidence and risk factors. A study from the European Collaborators on Stent/Graft Techniques for Aortic Aneurysm Repair (EUROSTAR) registry. J Vasc Surg. 2007;46:1103-10.

23. Dunning J, Martin JE, Shennib H, Cheng DC. Is it safe to cover the left subclavian artery when placing an endovascular stent in the descending thoracic aorta? Interact Cardiovasc Thorac Surg. 2008;7:690-7.

24. Weigang E, Luehr M, Harloff A, Euringer W, Etz CD, Szabó G, et al. Incidence of neurological complications following overstenting of the left subclavian artery. Eur J Cardiothorac Surg. 2007;31:628-36.

25. Murakami H, Yoshida K, Hino Y, Matsuda H, Tsukube T, Okita Y. Complications of cerebrospinal fluid drainage in thoracoabdominal aortic aneurysm repair. J Vasc Surg. 2004;39:243-5.

26. Jacobs MJ, Mommertz G, Koeppel TA, Langer S, Nijenhuis RJ, Mess WH, et al. Surgical repair of thoracoabdominal aortic aneurysms. J Cardiovasc Surg (Torino). 2007;48:49-58.

27. Cowan JA Jr, Dimick JB, Henke PK, Huber TS, Stanley JC, Upchurch GR Jr. Surgical treatment of intact thoracoabdominal aortic aneurysms in the United States: hospital and surgeon volume-related outcomes. J Vasc Surg. 2003;37: 1169-74.

28. Derrow AE, Seeger JM, Dame DA, Carter RL, Ozaki CK, Flynn TC, et al. The outcome in the United States after thoracoabdominal aortic aneurysm repair, renal artery bypass, and mesenteric revascularization. I Vasc Surg. 2001;34: 54-61.

29. Chuter TA. Fenestrated and branched stent-grafts for thoracoabdominal, pararenal and juxtarenal aortic aneurysm repair. Semin Vasc Surg. 2007;20:90-6.

30. Greenberg RK, West K, Pfaff K, Foster J, Skender D, Haulon S, et al. Beyond the aortic bifurcation: branched endovascular grafts for thoracoabdominal and aortoiliac aneurysms. J Vasc Surg. 2006;43:879-86. 